\title{
PENINGKATAN KEMAMPUAN KONSEP BILANGAN BERBANTUAN MEDIA PAPAN FLANNEL DI SD NEGERI 1 DOPANG
}

\author{
Sri Muryanti ${ }^{1, *)} \&$ Baiq Syahruniwati ${ }^{2)}$ \\ ${ }^{1), 2)}$ SD Negeri 1 Dopang, Lombok Barat, Indonesia \\ E-mail: asrimuryanti66@gmail.com
}

\begin{tabular}{|c|c|}
\hline ARTICLE INFO & ABSTRAK \\
\hline $\begin{array}{l}\text { Article history } \\
\text { Received: August 13, } 2020 \\
\text { Revised: August 15, } 2020 \\
\text { Accepted: August 17, } 2020 \\
\text { Kata Kunci: } \\
\text { konsep bilangan, media } \\
\text { pembelajaran, papan flanel }\end{array}$ & $\begin{array}{l}\text { Penelitian ini dilatar belakangi hasil pengamatan dan pengalaman peneliti, } \\
\text { bahwa kemampuan mengenal konsep bilangan kelompok di SDN } 1 \text { Dopang } \\
\text { masih rendah. Hal tersebut disebabkan penggunaan media belajar yang } \\
\text { hanya terbatas pada buku majalah, sehingga kurang menarik minat belajar } \\
\text { siswa. Penelitian ini menggunakan pendekatan Penelitian Tindakan Kelas } \\
\text { (PTK) dengan subjek penelitian adalah siswa kelas } 6 \text { SDN } 1 \text { Dopang dengan } \\
\text { jumlah } 32 \text { siswa. Penelitian dilaksanakan dalam tiga siklus, menggunakan } \\
\text { instrumen berupa RPPM, RPPH, Lembar Observasi, Kegiatan Pembelajaran } \\
\text { dan Lembar Penilaian Siswa. Hasil penelitian menunjukkan bahwa, terjadi } \\
\text { peningkatan hasil belajar dari setiap siklus. Persentase ketuntasan belajar } \\
\text { siswa pada siklus I adalah 54,9\%. Pada siklus II meningkat menjadi } 64,6 \% \\
\text { dan pada siklus III mencapai 80,6\%. Dengan demikian dapat disimpulkan } \\
\text { bahwa pemanfaatan media papan flanel dalam pembelajaran terbukti dapat } \\
\text { meningkatkan kemampuan kognitif pada siswa. Berdasarkan simpulan hasil } \\
\text { penelitian ini, direkomendasikan : (1) Bagi guru SD hendaknya dalam } \\
\text { pembelajaran menggunakan medialalat yang menarik dan mudah diingat; (2) } \\
\text { Bagi orang tua hendaknya di rumah menyediakan fasilitas dan senantiasa } \\
\text { membimbing, mengarahkan, dan mendampingi aktivitas siswa dengan baik; } \\
\text { (3) Bagi lembaga hendaknya menyiapkan sarana dan prasarana yang } \\
\text { memadai untuk meningkatkan prestasi hasil belajar siswa. }\end{array}$ \\
\hline
\end{tabular}

\section{A. PENDAHULUAN}

Pendidikan dasar siswa dapat diperoleh melalui jalur pendidikan informal secara formal yaitu Sekolah Dasar (SD) yang memberikan pelayanan pendidikan bagi siswa. Di SD, siswa akan dididik dan dilatih berbagai bidang pengembangan pembiasaan yang meliputi moral, nilai-nilai agama, sosial, emosional dan kemandirian (Basri et al., 2013). Disana pula, siswa juga dididik dengan berbagai bidang pengembangan kegiatan pembelajaran yang meliputi bahasa, kemampuan logika, fisik motorik dan seni. Aspek-aspek perkembangan siswa meliputi perkembangan nilai-nilai moral dan agama, sosial emosional, bahasa, kognitif dan fisik motorik (Nugroho, 2017). Aspek perkembangan tersebut tidak berkembang secara sendiri-sendiri melainkan saling terintegrasi satu sama lain. Perkembangan kognitif merupakan salah satu aspek yang penting untuk dikembangkan karena berkaitan dengan kemampuan berpikir dan kemampuan memecahkan masalah (Maulyda et al., 2019). 
Kemampuan kognitif yang berkembang dengan baik akan sangat mendukung bagi perkembangan bahasa dan motorik siswa. Dengan kemampuan mengolah informasi atau proses berpikir yang baik, siswa mampu memahami peristiwa yang dilihat dan didengarnya (Kefalis \& Drigas, 2019). Selanjutnya mereka memberi respons dengan cara mengungkapkan gagasan yang ada dalam otaknya dengan bahasa yang masih sederhana. Siswa juga dapat mengekspresikan diri melalui tindakan dengan menggerakkan anggota tubuh. Peningkatan kemampuan kognitif siswa juga berpengaruh positif bagi perkembangan nilai-nilai agama dan moral serta sosial emosional siswa (Maulyda et al., 2020). Hal ini berkaitan dengan kemampuan siswa dalam membedakan perbuatan yang baik dan perbuatan tidak baik. Siswa dapat memahami konsep moral dan aturan melalui proses berpikir dan penalaran terhadap suatu peristiwa (Depdiknas, 2007).

Tujuan pengembangan kemampuan kognitif adalah agar siswa dapat mengolah kemampuan belajarnya, dapat menemukan berbagai alternatif pemecahan masalah, membantu mengembangkan kemampuan logika matematika, pengetahuan ruang dan waktu, kemampuan untuk memilah-milah, mengelompokkan serta mempersiapkan kemampuan berpikir teliti (Depdiknas, 2004). Dengan demikian, tujuan pengembangan kognitif pada pendidikan siswa SD diarahkan agar siswa dapat mengonstruksi pengalaman belajar melalui interaksi objekobjek belajarnya. Menurut Nesbit \& Leacock (2019), kemampuan adalah kapasitas seseorang individu untuk mengerjakan berbagai tugas dalam suatu pekerjaan. Selanjutnya totalitas kemampuan dari seseorang individu pada hakikatnya tersusun dari dua perangkat faktor, yakni kemampuan intelektual dan kemampuan fisik (Maulyda et al., 2020). Kemampuan intelektual adalah kemampuan untuk menjalankan kegiatan mental. Kemampuan fisik adalah kemampuan yang diperlukan untuk melakukan tugas-tugas yang menuntut stamina, kecekatan, kekuatan dan bakat-bakat sejenis.

Tujuan program kegiatan belajar siswa SD adalah untuk membantu meletakkan dasar ke arah perkembangan sikap pengetahuan, keterampilan dan daya cipta yang diperlukan oleh siswa didik dalam menyesuaikan diri dengan lingkungannya dan untuk pertumbuhan serta perkembangan selanjutnya (Maulyda \& Khairunnisa, 2019). Salah satu bidang pengembangan kegiatan pembelajaran di SD yaitu bidang pengembangan ilmu matematika. Pengembangan ilmu matematika dapat diperoleh melalui kegiatan berhitung, membilang, mengelompokkan, mengenal bentuk, membedakan sesuatu dan lain-lain (Maulyda et al., 2020). Pembelajaran membilang pada siswa SD tidak terlepas dari angka-angka. Depdiknas (2007) menjelaskan bahwa pada siswa usia dini minat siswa terhadap konsep bilangan umumnya sangat besar. Di sekitar lingkungan kehidupan siswa, berbagai bentuk konsep bilangan yang sering ditemui 
misalnya: pada jam dinding, mata uang, ukuran, umur, kalender, irisan kue, jumlah buahbuahan, kepingan geometri, kartu angka, lambang bilangan, permainan kubus, pohon berhitung, bahkan konsep bilangan pada kue ulang tahun. Oleh karena itu dapat dikatakan bahwa konsep bilangan telah menjadi bagian dalam kehidupan kita sehari-hari, sehingga perlu diperhatikan pemahaman-pemahaman intelektual akan kuantitas secara simbolis tentang konsep bilangan pada siswa. Dengan demikian, pendidikan siswa usia dini terutama Taman Kanak-kanak senantiasa diarahkan pada upaya mengembangkan berbagai aspek perkembangan untuk mempersiapkan siswa didik agar menjadi individu yang mandiri dan kreatif (DjonkoMoore \& Joseph, 2016).

Menurut Toptaş \& Gözel (2018) konsep bilangan atau bilangan adalah lambang atau simbol yang merupakan suatu objek yang terdiri dari angka-angka. Sebagai contoh bilangan 10, dapat ditulis dengan dua buah konsep bilangan (double digits) yaitu konsep bilangan 1 dan konsep bilangan 10. Bilangan banyak ditemui dalam kehidupan sehari-hari. Namun demikian, bilangan yang ditemui siswa-siswa sebenarnya memiliki arti yang berbeda-beda. Salah satu kompetensi yang harus dimiliki oleh peserta didik Sekolah Dasar adalah mampu mengikuti pendidikan selanjutnya dengan kesiapan yang optimal sesuai dengan tuntutan yang berkembang dalam masyarakat (Indraswati et al., 2020). Kemampuan dasar yang dikembangkan di Sekolah Dasar meliputi kemampuan bahasa, fisik/motorik, seni dan kemampuan kognitif. Pengembangan kemampuan kognitif bertujuan meningkatkan kemampuan berpikir siswa. Pada kemampuan kognitif tersebut, siswa diharapkan dapat mengenal konsep sains dan matematika sederhana. Menurut Hidayati et al (2020), media merupakan sesuatu yang dapat digunakan untuk menyalurkan suatu informasi sehingga dapat merangsang pikiran, perasaan, perhatian dan minat siswa sehingga terjadi proses belajar. Istilah media dalam bidang pembelajaran disebut juga media pembelajaran, alat bantu atau media tidak hanya dapat memperlancar proses komunikasi akan tetapi dapat merangsang siswa untuk merespons dengan baik segala pesan yang disampaikan.

Papan flanel adalah media grafis yang efektif untuk menyajikan pesan-pesan tertentu pula. Papan berlapis kain flanel ini dapat dilipat sehingga praktis. Gambar-gambar yang akan disajikan dapat dipasang dan dicopot dengan mudah sehingga dapat dipakai berkali-kali, selain gambar, dikelas-kelas permulaan sekolah dasar atau taman siswa-siswa papan flanel ini dapat dipakai pula untuk menempelkan huruf dan angka-konsep bilangan karena penyajiannya seketika, selain menarik perhatian siswa penggunaan papan flanel dapat membuat sajian lebih 
efisien (Erfan et al., 2020). Kemampuan kognitif dalam mengenal konsep bilangan yang dimiliki setiap siswa berbeda. Ada yang cepat menerima, ada pula yang lambat.

Sebagai pendidik dan orang tua, hendaknya mengetahui permasalahan yang dihadapi oleh siswa dan mengupayakan solusi pemecahan masalah tersebut. Salah satu faktor yang menyebabkan kesulitan siswa dalam mengenal konsep bilangan adalah sarana dan prasarana yang digunakan oleh pendidik dan orang tua kurang menarik minat belajar siswa. Hal tersebut menjadikan siswa cenderung pasif, terbebani, mudah bosan dan berorientasi pada hafalan. Ditambah pula oleh tuntutan kurikulum yang mengharuskan penyampaian materi dengan target waktu tertentu, mendorong timbulnya pemaksaan oleh pendidik kepada siswa didik untuk menyelesaikan materi dengan cepat tanpa memikirkan proses, pendalaman dan pemahaman materi. Dampak yang sangat mungkin terjadi adalah hasil belajar siswa tidak tercapai secara optimal sehingga perkembangan siswa akan terganggu. Fenomena seperti uraian di atas terjadi di SDN 1 Dopang pada siswa-siswa kelompok Tahun ajaran 2019/2020.

\section{B. METODE PENELITIAN}

Penelitian ini dilaksanakan kepada siswa di SDN 1 Dopang, Gunung Sari, Kabupaten Lombok Barat, Nusa Tenggara Bar. 83351. Subyek penelitian ini adalah siswa kelas VI SDN 1 Dopang Tahun Ajaran 2019/2020 dengan jumlah siswa didik 32 siswa, yaitu 12 siswa lakilaki dan 20 siswa perempuan. Alasan dipilihnya kelompok tersebut sebagai subyek penelitian adalah karena peneliti merupakan salah satu pengasuh dilembaga tersebut, serta berdasarkan hasil pengamatan awal diketahui bahwa masih kurangnya kemampuan mengenal konsep bilangan masih relatif rendah. Untuk itu peneliti mencoba memperbaiki dengan melakukan tindakan pembelajaran melalui media papan flanel.

Penelitian ini merupakan Penelitian Tindakan Kelas (PTK). Menurut Gaspar, Tania, Cerqueira et al (2018) Penelitian Tindakan Kelas merupakan penelitian yang dilakukan oleh para guru di dalam kelasnya sendiri melalui refleksi diri, dengan tujuan untuk memperbaiki kinerjanya sebagai guru, sehingga hasil belajar siswa menjadi meningkat. Sedangkan menurut Creswell (2014) Penelitian Tindakan Kelas di Sekolah Dasar merupakan suatu kegiatan penelitian yang bertujuan untuk mengatasi permasalahan praktis dan nyata yang terjadi di kelas atau kelompok tertentu di Sekolah Dasar. Berdasarkan kedua pendapat tersebut dapat didefinisikan bahwa Penelitian Tindakan Kelas adalah kegiatan mencermati lalu mencari permasalahan dikelas dan mengatasi permasalahan melalui refleksi diri dengan tujuan untuk meningkatkan kualitas pembelajaran dikelas. 
Penelitian ini juga termasuk penelitian Deskriptif sebab penelitian Tindakan dimulai dari mencari informasi tentang keadaan sesuatu dalam mencari kelemahan dengan mendeskripsikan hal-hal yang terkait dengan kelemahan tersebut, selama penelitian tindakan berlangsung peneliti mengamati terjadinya tindakan kemudian mendeskripsikan dalam bentuk informasi (Sugiyono, 2006). Tindakan yang akan dilakukan dalam penelitian ini adalah meningkatkan kemampuan mengenal konsep bilangan menggunakan media papan flanel pada siswa Sekolah Dasar Negeri 1 Dopang. Media ini dipilih supaya siswa lebih tertarik, senang dan mudah dalam mengenal konsep bilangan menggunakan media papan flanel ini sangat menyenangkan. Melalui rancangan Penelitian Tindakan Kelas (PTK) yang digunakan mengacu pada rancangan model Kemmis dan McTaggart dengan 2 siklus (Sugiyono, 2006). Masingmasing siklus terdiri dari 4 tahapan, yaitu: penyusunan rencana tindakan, pelaksanaan tindakan, observasi / pengamatan dan refleksi. Adapun model PTK yang dimaksud menggambarkan adanya empat langkah (dan pengulangannya).

\section{HASIL DAN PEMBAHASAN}

Berdasarkan hasil penelitian yang telah dilaksanakan kepada siswa, kemampuan mengenal konsep bilangan menggunakan media papan flanel pada siswa SDN 1 Dopang pada siklus I, siklus II dan siklus III mengalami peningkatan setiap siklusnya. Hal ini dapat dilihat dari perbandingan hasil nilai siswa dalam tiap siklusnya. Hasil nilai siswa dalam kegiatan pengenalan konsep bilangan menggunakan media papan flanel adalah sebagai berikut:

Tabel 1. Hasil Penelitian Siklus I, II, dan III pada Kegiatan Mengenai Konsep Bilangan Menggunakan Media Papan Flannel

\begin{tabular}{|c|c|c|c|c|}
\hline No & Penilaian & $\begin{array}{c}\text { Tindakan } \\
\text { Siklus I }\end{array}$ & $\begin{array}{c}\text { Tindakan } \\
\text { Siklus II }\end{array}$ & $\begin{array}{l}\text { Tindakan } \\
\text { Siklus III }\end{array}$ \\
\hline 1 & 20 & $20 \%$ & $20 \%$ & $0 \%$ \\
\hline 2 & $\Leftrightarrow \Leftrightarrow$ & $46,7 \%$ & $20 \%$ & $6,7 \%$ \\
\hline 3 & $\Leftrightarrow \Leftrightarrow \Leftrightarrow$ & $20 \%$ & $40 \%$ & $40 \%$ \\
\hline \multirow[t]{2}{*}{4} & $\Leftrightarrow \Leftrightarrow \Leftrightarrow \Leftrightarrow$ & $13,3 \%$ & $20 \%$ & $53,3 \%$ \\
\hline & Jumlah & $100 \%$ & $100 \%$ & $100 \%$ \\
\hline
\end{tabular}

Hasil data siklus I, II dan III menunjukkan terjadi peningkatan ketuntasan belajar siswa pada kegiatan mengenal konsep bilangan menggunakan media papan flanel. Pada siklus I, ratarata ketuntasan belajar siswa mencapai 33,3\%. Rata-rata ketuntasan belajar pada siklus II mencapai $60 \%$ dan pada siklus III meningkat menjadi 93,3\%.

Berdasarkan hasil pengamatan peneliti dan hasil diskusi dengan guru, umumnya masih memiliki kemampuan kognitif yang rendah terutama membedakan angka. Keterbatasan media 
belajar menjadi salah satu penyebab rendahnya pemahaman siswa dalam memahami angka. Guru-guru di sana menggunakan media belajar mengenal konsep bilangan yang kurang menarik bagi siswa dijumpai di lapangan. Siswa mengenal konsep bilangan hanya dari media buku dan majalah. Data perkembangan siswa menunjukkan bahwa kemampuan mengenal konsep bilangan dari 30 siswa didik terdapat 4 siswa mendapatkan nilai bintang 4, 6 siswa mendapat nilai bintang 3, 8 siswa mendapat nilai bintang 2 dan 12 siswa mendapat nilai bintang 1. Maulyda (2020) menekankan pentingnya bermain bagi perkembangan kognitif dan kreativitas siswa. Bermain menyediakan aktivitas bagi siswa. Bila siswa beraktivitas berarti pikiran siswa juga berfungsi. Solusi yang dapat dilakukan untuk mengatasi masallah rendahnya kemampuan mengenal konsep bilangan ini adalah melalui perbaikan pembelajaran terutama berkenaan dengan media belajar.

\section{SIMPULAN}

Berdasarkan keseluruhan kegiatan penelitian tindakan kelas sebanyak dua siklus dapat disimpulkan bahwa terdapat peningkatan kemampuan peserta didik dalam menggali Informasi penting pada teks narasi sejarah berbantuan video pembelajaran di kelas VI SDN 1 Dopang. Hal ini dapat di lihat dari nilai Gain pada siklus I $(0,21)$ yang berada pada kategori rendah (belum signifikan) dan nilai Gain pada siklus II $(0,57)$ yang berada pada kategori sedang (cukup signifikan).

\section{DAFTAR PUSTAKA}

Basri, H., Syakur, \& Aris Marta. (2013). Penyimpangan Penggunaan Lahan Berdasarkan Rencana Tata Ruang Wilayah Kabupaten Aceh Barat. Rona Teknik Pertanian, 6(1), 383-397.

Creswell, J. W. (2014). Research Design: Qualitative, Quantitative and Mixed Methods Approaches (4th ed.). SAGE.

Djonko-Moore, C. M., \& Joseph, N. M. (2016). Out of the Classroom and Into the City. SAGE Open, 6(2), 212-220. https://doi.org/10.1177/2158244016649648

Erfan, M., Maulyda, M. A., Gunawan, G., Sari, N., \& Ratu, T. (2020). Enhancing Students Ability in Analyzing Image Formation on Lens and Mirror Using Ray Optics. Journal of Physics: Conference Series, 1471(1). https://doi.org/10.1088/1742$\underline{6596 / 1471 / 1 / 012061}$

Gaspar, Tania, Cerqueira, A., Branquinho, C., \& Matos, M. G. De. (2018). Original Research Article Original Research Article Open Access Dimensions of Social and Personal 
Skills in Children and Adolescents : Age and Gender Differences. International Journal of Development Research, 08(February), 18394-18400.

Hidayati, V. R., Wulandari, N. P., Maulyda, M. A., Erfan, M., \& Rosyidah, A. N. K. (2020). Literasi Matematika Calon Guru Sekolah Dasar dalam Menyelesaikan Masalah PISA Konten Shape \& Space. JPMI: Jurnal Pembelajaran Matematika Inovatif, $3(3), 1-10$.

Indraswati, D., Satrio, T., Maulyda, M. A., Erfan, M., Widodo, A., \& Rahmatih, A. N. (2020). Leadership of School Principal and Advertising Question to the Teachers Work Motivation. International Journal of Advances in Social and Economics, 2(3). https://doi.org/10.33122/ijase.v2i3.165

Kefalis, C., \& Drigas, A. (2019). Web Based and Online Applications in STEM Education. International Journal of Engineering Pedagogy, 9(4), 76-85.

Maulyda, M. A., Rahmatih, A. N., Gunawan, G., Hidayati, V. R., \& Erfan, M. (2020). Retroactive Thinking Interference of Grade VI Students: A Study on the Topics of PISA Literacy Lessons. Journal of Physics: Conference Series, 1471(1), 1-7. https://doi.org/10.1088/1742-6596/1471/1/012037

Maulyda, M A, Annizar, A. M., Hidayati, V. R., \& Mukhlis, M. (2020). Analysis of students' verbal and written mathematical communication error in solving word problem. Journal of Physics: Conference Series, 1538, 012083. https://doi.org/10.1088/1742$\underline{6596 / 1538 / 1 / 012083}$

Maulyda, Mohammad Archi, Hidayanto, E., \& Rahardjo, S. (2019). Representation of Trigonometry Graph Funcsion Colage Students Using GeoGebra. International Journal of Trends in Mathematics Education Research, 2(4), 1-7.

Maulyda, Mohammad Archi, \& Khairunnisa, G. F. (2019). Profil kesalahan mahasiswa dalam menggambar grafik fungsi rasional. MaPan: Jurnal Matematika Dan Pembelajaran, 7(2), 181-193.

Maulyda, Mohammad Archi, Sukoriyanto, S., Hidayati, V. R., Erfan, M., \& Umar, U. (2020). Student Representation in Solving Story Problems Using Polya Steps. Formatif: Jurnal Ilmiah Pendidikan MIPA, 10(1), 25-34. https://doi.org/10.30998/formatif.v10i1.4629

Maulyda, Mohammad Archi, Umar, Erfan, M., Hidayati, V. R., \& Haryati, L. F. (2020). IMPLEMENTATION OF STAD TYPE COOPERATIVE LEARNING TO 
Muryanti, dkk. (2020). Meningkatkan Kemampuan Peserta...

IMPROVE MATHEMATICAL LEARNING OUTCOMES CLASS VIII STUDENTS. Jurnal Ilmiah Pendidikan Matematika, 5(1), 1-12.

Nesbit, J. C., \& Leacock, T. L. (2019). Web-Based Tools for Collaborative Evaluation of Learning Resources. SYSTEMICS, CYBERNETICS AND INFORMATICS VOLUME, 3(5), 102-112.

Nugroho, A. A. (2017). The implementation of collaborative-based guided discovery reviewed from students' analytical thinking skills and social skills. Jurnal Inovasi Pendidikan IPA, 3(2), 128. https://doi.org/10.21831/jipi.v3i2.14508

Sugiyono. (2006). Metode penelitian kuantitatif kualitatif dan $R \& D$. Alfa Beta.

Toptaş, V., \& Gözel, E. (2018). Investigation of the Metaphorical Perceptions of the Parents on the Concept of " Mathematics ." International Electronic Journal of Elementary, 10(5), 621-626. https://doi.org/10.26822/iejee.2018541311 